\title{
Development of tourism in the Third World nations: a comparative analysis
}

\author{
A. Sharma \& M. Thapar \\ Hidayatullah National Law University, India
}

\begin{abstract}
The tourism sector is one of the most profitable non-technology-based-economic sectors and, more so in the case of Third World nations, which will remain as this research paper's prime focus. At that, we should keep in mind the hurdles embedded in such countries - abject poverty, dearth of educational and employment opportunities and lack of capital, to name but a few. This paper primarily deals with the relative plusses of progress in the tourism sector over advances in the technological sector, insofar as Third World nations are concerned. So, a dependence of such nations (and/or local communities, as the case may be) on the tourism department gives them an upper hand over the technology-based-economic sectors. Such nations have unharnessed and unexploited natural resources and scenic landscapes which attract tourists massively, especially from the First World nations. Also, in such time of unchecked economic expansion, life as such becomes exceedingly hectic. Thus, such tourist destinations become, though temporarily, the much needed escape from this monotonous lifestyle that we lead, as has been further elucidated in the paper. Furthermore, this paper also discusses how alternative tourism policies and strategies that put the interests of local ethnic and indigenous communities to the fore can profit dually - one, by benefitting the tourism sector and two, by bestowing upon such communities an opportunity to be self-sufficient. This, in turn, would foster the process of nation building and help in reduction of soaring rates of poverty and unemployment. This paper is researched upon secondary external data taken from various journals and research theses, with due regard, salutations and proper citations to the source of the data, as and when required.

Keywords: sustainable tourism, local communities, technology-based-economic sectors, growth, development.
\end{abstract}




\section{Introduction}

Among the myriad of issues that Third World nations face, in general, the primary ones have always been abject poverty and lack of facilities - of education, of employment and of health care alike. Prolonged existence of such problems may give rise to social and cultural exclusion - a state of the society which makes it go haywire with absolute absence of law and order. Without delving deeper into what the root causes of such vexations are, let's look at how possible re-arrangements in strategies and alternative policies on development and growth can foster the process of nation-building, keeping in mind the characteristics of Third World nations - let's see how the tourism industry, though nascent, can be a key player in the progress of a country.

But, before we delve deeper into the topic in hand, let's define the concept of Third World nations. Coined in the 1950s by the French writer Alfred Sauvy (as 'le tiers monde'), it was originally used in the Cold War era (1945-89) to distinguish non-aligned nations from the Western capitalist economies aligned with the US (the First World) and the Eastern communist economies aligned with the USSR (the Second World). In common parlance, "Third World" is a collective name for most of the nations of Africa, Asia, Latin America, and the Middle East, many of which share a colonial past and are variously termed as developing, less developed, or least developed countries. They support $75 \%$ of the world's population but consume only $20 \%$ of its resources, and are generally characterized by
A. slow pace of industrialization;
B. low to very low levels of per capita income that is insufficient to generate savings for economic growth;
C. low literacy levels but a high rate of population growth;
D. poor health facilities and transport infrastructure and
E. dependence on agricultural and commodity exports as main foreign exchange earners.

\section{Sustainable tourism: the status quo}

Having unique indigenous cultures, nature-based attractions, beautiful landscapes, and pleasant weather conditions, local communities in Africa, and other Third World countries, are increasingly being promoted and marketed in major tourist generating countries, particularly in Europe and North America, as offering immense touristic and recreational opportunities. Particularly, indigenous communities in the Third World are perceived as providing abundant opportunities for rich tourists from the First World nations who have got the financial resources to spend in adventure and exotic recreational activities. As a consequence, an increasing number of international tourists are travelling to different tourist destinations in Africa and other less developed regions of the world. In 2001 for instance, over 28 million international tourists, mainly from Europe and North America, travelled to different destinations in Africa. It is 
further estimated that with the current international growth rate of the tourism industry, over 77 million international tourists will visit Africa by the year 2020 [1].

Neo-classical economists and development experts contend that unlike factor driven technology based development, local communities in Africa and other parts of the Third World have a comparative advantage in the development of tourism and other non-technology based economic sectors. The development of tourism amongst local communities is therefore perceived as fitting quite well with the 'natural process of development based on comparative advantage' [2]. This argument is based upon the presumption that local communities should mainly specialize in primary exports, including tourism, where they have comparative advantage rather than depending on technology based economic sectors that do not conform to the principles of comparative advantage in the global market demand.

Many Western tourists are haggling for these forms of touristic attractions in order to escape from the perceived monotony of everyday life in the often overcrowded and congested urban conglomerates. In this regard, tourists want to travel to other places, albeit temporarily, in order to escape from the monotony of routine life and are, therefore, looking for alternative environments that are perceived as having fascinating indigenous cultures and pristine nature attractions.

Furthermore, it should also be stated that, in most instances, the debate on the efficacy of tourists as a tool for sustainable local community development is mainly conducted in the international and/or national arena, whereas there is minimal analysis that is conducted on tourism development at local community grassroots level. Particularly, there is a paucity of information on socio-cultural and economic impacts of tourism development on local communities in such said nations and on the existing forms of interaction between tourists and host communities. This scenario should be of major concern when realizing that tourism has become a major socio-economic and cultural phenomenon affecting local communities in parts of the Third World.

For instance, it has been observed in different parts of the world, particularly in many Third World countries, that the rapid development of mass tourism can overwhelm local communities and the environment having far-reaching negative socio-ecological and economic impacts. Moreover, tourism can contribute to the exacerbation of the already existing socio-economic division and inequity by widening the gap between the beneficiaries of tourism and those who are already marginalized by the current forms of development.

Consequently, to be of any meaning to marginalized local communities and individuals, especially in developing countries such as Kenya, tourism development should be viewed as being part of a broader alternative policy framework that is designed to achieve a sustainable society. Tourism development should therefore not be seen as an end in itself, but should be viewed as one of several alternative development strategies that can assist local communities in overcoming their socio-economic and developmental weaknesses, preserving their strengths and enhancing their 
developmental opportunities. Furthermore, in order to put in proper perspective the role of tourism as a tool for sustainable local community development, it is important to analyse the forms of tourism employment undertaken by the local people.

USA Today defines sustainable tourism as "the concept of visiting a place as a tourist and trying to make only a positive impact on the environment, society and economy." As one of the world's largest and fastest growing industries, this continuous growth will place great stress on remaining biologically diverse habitats and indigenous cultures, which are often used to support mass tourism. Tourists who promote sustainable tourism are sensitive to these dangers and seek to protect tourist destinations, and to protect tourism as an industry [3].

\subsection{Stakeholder analysis}

Stakeholders of sustainable tourism play a very crucial role in the development of sustainable development. As rightly elucidated by Aas et al. [4], "A stakeholder in the tourism industry is deemed to be anyone who is impacted on by development positively or negatively, and as a result it reduces potential conflict between the tourists and host community by involving the latter in shaping the way in which tourism develops". The international body, Global Sustainable Tourism Council (GSTC), stands as the regulatory body for fostering increased knowledge and understanding of sustainable tourism practices, promoting the adoption of universal sustainable tourism principles and building demand for sustainable travel [5]. Amongst other stakeholders, the major ones are the local communities and the government so concerned.

Since this research paper recognizes, specifically, the effects of sustainable tourism on the local and ethnic communities and tribes - here is an overview of the same.

\subsubsection{Stakeholder analysis of sustainable tourism on the local communities}

Local communities benefit from sustainable tourism through economic development, job creation, and infrastructure development [6]. Tourism revenues bring economic growth and prosperity to attractive tourist destinations which can raise the standard of living in destination communities. As per WTTC, nearly 260 million jobs worldwide are supported by travel and tourism, either directly in the industry or in related sectors. These jobs are vital not only for the livelihoods of those employed, but also for their families and the wider communities in host destinations [7]. Sustainable tourism operators commit themselves to creating jobs for local community members. Increase in tourism revenue to an area acts as a driver for the development of increased infrastructure. As tourist demands increase in a destination, a more robust infrastructure is needed to support the needs of both the tourism industry and the local community [8].

Sustainable tourism concept is a concept that sets forth the delivery of the environmental, economical and social resources to next generations without any destruction. The local community and the local enterprises are the most affected sides from the development of tourism activities in a region. Within this context, 
opinions and proposals of local community and other shareholders are important for the conservation of natural, cultural and historical factors especially in touristic region and in its surroundings. From this point of view, the controlled, systematic and balanced improvement of the tourism sector may be provided by more responsible behaviours of all shareholders to each other, and by developing a balanced plan that takes the demands and expectations of local community into consideration, minimizes the mistakes, reconciles the interests of enterprises and local 83 community as a result of social participation. Thus, long-term important successes can be achieved and conservation of resources and their delivery to future generations can be provided within sustainable tourism concept [9].

\section{Sustainable tourism as a part of development strategy}

Third World countries are especially interested in international tourism [10], and many believe it brings countries a large selection of economic benefits including employment opportunities, small business development, and increased in payments of foreign exchange. Many assume that more money is gained through developing luxury goods and services in spite of the fact that this increases a countries dependency on imported products, foreign investments and expatriate skills [11]. This classic 'trickle down' financial strategy rarely makes its way down to benefit people at a grassroots level [12].

It has been said that the economic benefits of large-scale tourism are not doubted but that the backpacker or budget traveller sector is often neglected as a potential growth sector by Third World governments [13]. This sector brings significant non-economic benefits, which could help to empower and educate the communities involved in this sector. "Aiming 'low' builds upon the skills of the local population, promotes self-reliance, and develops the confidence of community members in dealing with outsiders, all signs of empowerment" [13] and all of which aid in the overall development of a nation.

So, now that we have encompassed the concept of sustainable tourism, one may as - what exactly is the point of achieving the ideals behind the aforesaid? In Maori, there is a famous proverb - Toitü he whenua, whatungarongaro he tangata. In other words, it means that land is permanent but man is not.

We live at a time when there is a growing concern about climate decimation and environmental pollution. At the same time, the Third World nations are trying to forge a separate identity of their own in the international arena. Unfortunately, to mark such an identity, one also needs to make its presence felt and, to make such a presence to be felt internationally, there needs to be development in such said nation of the Third World cadre.

So, hereon, this paper shall elucidate how sustainable tourism is actually the best of the bets such nations have to garner more and more international cognizance. And, also, we shall talk about how an investment in the tourism sector is far more smart an idea than fostering growth in the technology based economy sector. 


\subsection{Sustainable tourism against technology based economic sector}

According to various reports of the World Tourism Organization, in the year of 2000 alone there was a humongous expenditure of over USD 478 billion by over 700 million people travelling to a foreign nation for tourism and sightseeing. Such figures do not include the visits made to a foreign land for personal meets and business meets. Also, international tourism receipts combined with passenger transport add up to over USD 575 billion. Thus, according to facts and figures of circa $2000 \mathrm{AD}$, tourism tops over automotive products, chemical exports and petroleum exports and food trade, making it the number one earner. And, the aforementioned facts and figures adhere only to the tourism export business. In this, we are not even including the income that would be generated because of the vast employment generation.

Figure 1 portrays the steady growth of international tourist arrivals and international tourist arrivals since 1950. Under closer scrutiny we can observe that there has been a dramatic rise in the former since 1985 .

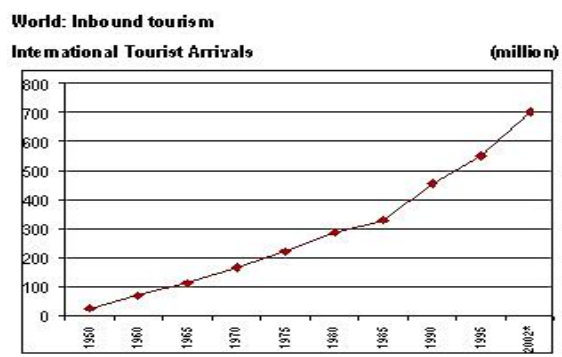

World: Inbound touris m

Intemational Tourist Arrivals

International Tourism Receipts (US\$ billion, current prices)

Source: World Tourism Organization (NuTO) 9



Figure 1: Growth of international tourist arrivals and international tourist arrivals since 1950 .

Figure 3 is a continent wise division as to the number of voyages made by tourists. Tourism as a sector is so vastly developing and so steadily growing that the period of January-August 2004, saw an overwhelming $12 \%$ growth rate, which is 58 million people travelling to other nations for sightseeing!

Now, that was all about how tourism as a sector of economic development is a forte in itself. When compared to technology-based-economic sectors, keeping in mind that we are referring to Third World nations, we also need to keep other facets in mind.

Sustainable tourism aims at giving people a closer look at the nature that they have long turned a blind eye to. Partly, because of the paucity of time people have in their life to connect with it and partly because spots for such tourism are not in abundance, anymore. Environmental pollution has, to a very large extent, gulped down a lot of scenic spots, leaving such spots in a despicable condition. If we look at the facts and figures carefully, we can observe that most of the tourists who travel to such different lands are from First World nations. The reason behind this is that the mechanised lifestyle that people in such First World 
nations usually lead is mechanized and monotonous, usually - deadlines and the corporate work culture usually eats up most of their time. So, evidently, the desire for a break from such a lifestyle brings them to travel to places which have that scenic and aesthetic and picturesque value to them - simply put, the Third World nations, which offer a lot of beauty and serenity.

This, in turn, motivates such economically backward Third World nations to promote themselves as a tourist destination. This system of tourists from foreign lands visiting and such Third World nations becoming hosts works on the basic principles of demand-and-supply. And, in turn, the tourists also come in interaction with the local and ethnic communities of the Third World nations, aforementioned. This, also, paves way for a higher understanding between people and cultures. Such understanding, ultimately, helps in the process of harmonizing nations and the common will of people - which, in the long run, helps foster a sense of fraternity and brotherhood.

In Table 1, we have made an attempt to show the comparisons between three Third World nations, namely, Kenya, India and Nigeria. The three nations have different, non-exclusive traits and happen to be belonging to two different continents with varying cultural and ethno-demographic characteristics. But, the three of these countries have one similarity, i.e., the tourism sector, which accounts for a considerable part of their respective GDPs.

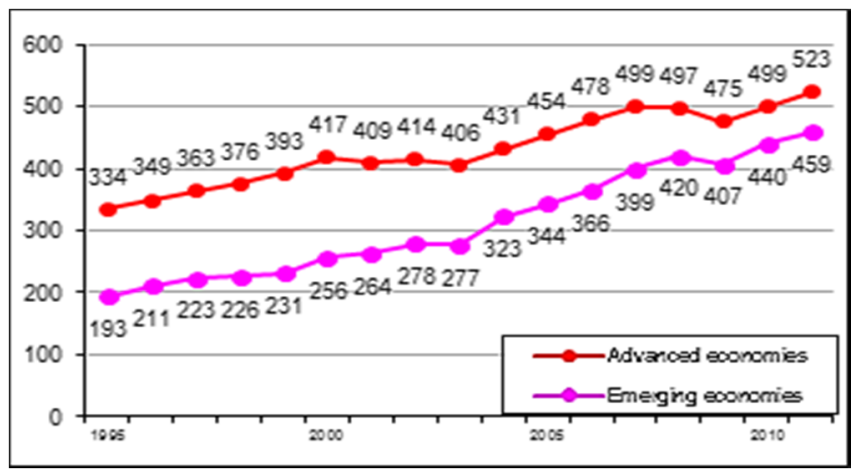

Figure 2: Comparison of the GDPs different countries based on their economic prowess for a period of 1995-2010.

\section{The special importance of sustainable tourism in poverty alleviation in Third World nations}

Taking the idea of development of the people of the said Third World nations one step ahead, here is how sustainable tourism can be a pole-bearer when it comes to poverty alleviation of people and betterment in their standards of living. 


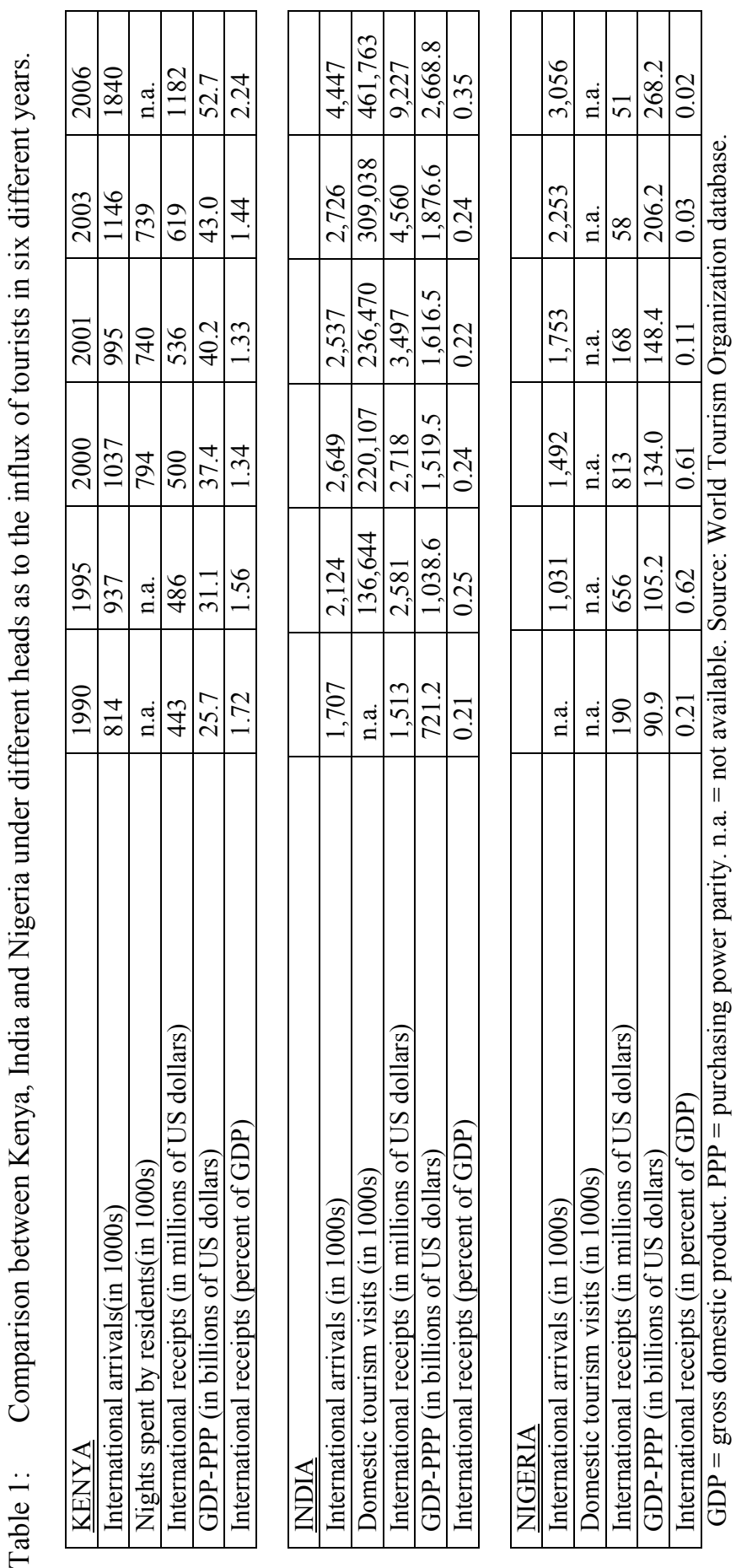




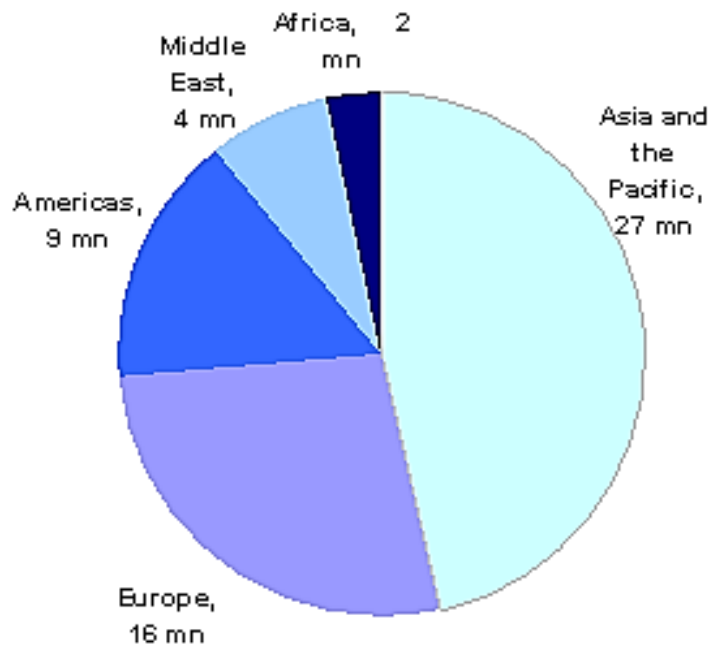

Figure 3: Increase in international tourism arrivals January-August 2004, worldwide 58 million.

\subsection{The size and growth of the sector}

In many countries, tourism acts as an engine for development through foreign exchange earnings and the creation of direct and indirect employment. Tourism contributes $5 \%$ of the world's GDP. It accounts for $6 \%$ of the world's exports in services being the fourth largest export sector after fuels, chemicals and automotive products. Tourism is responsible for 235 million jobs or one in every 12 jobs worldwide.

In 2011, international arrivals grew by over 4\% reaching 982 million, up from 939 million in 2010, in a year characterized by a stalled global economic recovery, major political changes in the Middle East and North Africa and natural disasters in Japan.

\subsection{The relative importance of tourism in developing nations}

Tourism in many developing and least developed countries is the most viable and sustainable economic development option, and in some countries, the main source of foreign exchange earnings. Part of this income trickles down to different groups of the society and, if tourism is managed with a strong focus on poverty alleviation, it can directly benefit the poorer groups through employment of local people in tourism enterprises, goods and services provided to tourists, or the running of small and community-based enterprises, etc, having positive impacts on reducing poverty levels. 
Tourism in the recent years has been characterized by two main trends; firstly, the consolidation of traditional tourism destinations, like those in Western Europe and North America; and secondly, a pronounced geographical expansion. There has been a substantial diversification of destinations, and many developing countries have seen their tourist arrivals increase significantly. Arrivals to developing countries accounted for $46 \%$ of the total international arrivals in 2011. Tourism has become a major player in the economy of developing countries.

Here are some facts:

i. In 2011, international tourism arrivals to emerging market and developing countries amounted to 459 million.

ii. Tourism is the first or second source of export earnings in 20 of the world's 48 least developed countries.

iii. In some developing countries, notably small island states, tourism can account for over $25 \%$ of GDP (Figure 2 ).

\subsection{The character of tourism}

There are many characteristics of tourism as an activity, which make it particularly relevant to low income countries, and to poor communities within them. These include:

- Its response to particular assets - tourism places great value on some common features of developing countries, such as warm climate, rich cultural heritage, inspiring landscapes and abundant biodiversity. These strengths can be particularly apparent in rural areas, which may have a comparative advantage for tourism while being at a disadvantage in most other economic sectors.

- Its accessibility to the poor - tourism is a relatively labour intensive sector and is traditionally made up of small and micro enterprises. Many activities in tourism are particularly suited to women, young people and disadvantaged groups such as ethnic minority populations. Many tourism jobs are potentially quite accessible to the poor as they require relatively few skills and little investment. Some may also be part time and used to supplement income from other activities.

- Its connectivity - as so many different activities and inputs make up the tourism product, which has a large and diversified supply chain, spending by tourists can benefit a wide range of sectors such as agriculture, handicrafts, transport and other services. Additional rounds of spending by those people whose income is supported by tourism spread the economic benefit further (the multiplier effect).

- Its linking of consumers to producers - tourism, unusually, is an activity which brings the consumers to the producers. The interaction between tourists and poor communities can provide a number of intangible and practical benefits. These can range from increased awareness of cultural, environmental, and economic issues and values, on both sides, to mutual benefits from improved local investment in infrastructure [14]. 


\section{Conclusions}

As emphasized upon in the beginning of the paper, sustainable tourism development is not a one-man job; rather, it needs participation from all fronts, including that of major players like the respective governments and the local and ethnic tribes and communities as well. Tourism, as an industry and a source of economic growth, is going to have a boom in the near future. And, speaking strictly for the Third World nations, tourism shall be their stalwart in the development process. Not only would such communities and Governments gain from this spurge of the tourism industry, but also will such tourists who primarily hail from the First World countries and seeking for a memorial escape to the nature's aesthetic beauty.

Higher earnings from the tourism sector would also mean, in the longer run, better standards of living. This, in turn, also ensures a considerably lesser crime rate scenario, as well as a rather peaceful society. Not only this, tourism sector would open doors for a higher rate of employment for the citizenry at large.

Coming over to the other aspect, a continuous influx of people from different nations and different acculturations would also pave way for a greater understanding of each other's cultures.

Not only this, it's also important to keep in mind that sustainable tourism also has a major role in preserving the environment. At an age of unsurpassed technological dexterity, the techno-economic sector is at its zenith. But, considering the fact that sustainable tourism provides for an alternative solution of higher economic development, with better incentives associated like having ecologically cleaner an environment.

Now, the goals of sustainable development have not been achieved yet - there is a significant number of hurdles, which need to be addressed. Nevertheless, the distance covered has been considerable and programs implemented successful. Special emphasis is being in evolving new methods at the micro-levels to give a better definition to the concept of sustainable tourism. And, all of this is for the reason that sustainable tourism holds a lot of promise is safeguarding the interests of not just nature, but also of the Third World nations and their local communities, who are one of the prime stake-holders and much so deservedly.

And, to the nature that we so owe pretty much everything we have - we have a duty as being the only beings with the faculty of thought to discern the fact that we ought to leave this world a better place than as it was when we arrived here.

For we do not inherit the earth from our ancestors; we borrow it from our children.

\section{References}

[1] Press release of the World Tourism Organization (UNWTO), http://media.unwto.org/press-release/2014-12-18/international-tourismtrack-end-2014-record-numbers 
[2] New Directions in Tourism for Third World Development, John Brohman, http://citeseerx.ist.psu.edu/viewdoc/download?doi=10.1.1.330.6563\&rep= rep1\&type $=$ pdf

[3] USA Today, http://traveltips.usatoday.com/meaning-sustainable-tourism2297.html

[4] Aas, C., Ladkin, A., Fletcher, J. (2005). "Stakeholder collaboration and heritage management". Annals of Tourism Research 32 (1): 28-48.

[5] GSTC, http://sustain.pata.org/partnerships/gstc/

[6] Choudhary, R., Sustainable Tourism in India: Collective Efforts of Tourism Stakeholders, Vol. 1(1), p. 82, 2014

[7] Biwal, A., Roday, S. \& Bhave, S., Designing a Training Module to Encourage Best Practices in Community Based Ecotourism, Vol. 4, p. 2, 2015

[8] Prezi, https://prezi.com/pxxxd0uwmqx8/sustainable/

[9] Tosun, C. (2000). Limits to Community Participation in The Tourism Development Process In Developing Countries. Tourism Management 21, 613-633.

[10] Harrison, D (1992).International Tourism in the less developed countries. Chichester: Wiley. pp. 1-18.

[11] Baskin, J (1995). Local economic development: Tourism - Good or Bad? In Tourism workshop proceedings: small, medium, micro enterprises. Johannesburg: Land and Agriculture Policy Center. pp. 102-116.

[12] Scheyvens, R (1999). "Ecotourism and the Empowerment of Local Communities" Tourism Management 20: 245-249

[13] Scheyvens, R (2002). Backpacker tourism and third world development. Annals of Tourism Research. 1 29: 144-164.

[14] UNWTO Tourism and Poverty Alleviation, http://step.unwto.org/ content/tourism-and-poverty-alleviation-1 